\title{
Um Hiperdocumento para Introdução à Geometria Plana
}

\author{
Adriana Justin Cerveira Kampff* \\ André Luís Andrejew Ferreira* \\ Maria Helena Sório de Carvalho \\ José Valdeni de Lima
}

\begin{abstract}
This article presents the motivation, the theories, the modeling and the implementation of a multimedia environment prototype, a hyper document with didactic ends, for support to the education and the learning of Elementary Plain Geometry. The material leads with the abilities and contents to be developed in Plain Geometry, in the discipline of Mathematic, in Basic Level School. Thus, it is considered as potential public of this multimedia product the students of the $5^{a}$ to the $8^{a}$ series of this level of education. The described material search to explore concepts of interactive form, demanding active and intentional participation of the user, and to stimulate the resolution of problems based in daily situations, as the National Curricular Parameters (PCNs).
\end{abstract}

Keywords: hyper document, Plain Geometry.

Resumo. Este artigo apresenta a motivação, os referenciais, a modelagem e a implementação de um protótipo de ambiente multimídia, um hiperdocumento com fins didáticos, para suporte ao ensino e à aprendizagem da Geometria Plana Elementar. O material abarca competências e conteúdos a serem desenvolvidos em Geometria Plana, na disciplina de Matemática, no Ensino Fundamental. Assim, considera-se como potencial público-alvo desse produto multimídia os estudantes de $5^{a}$ a $8^{a}$ série desse nível de ensino. O material descrito busca explorar conceitos de forma interativa, exigindo participação ativa e intencional do usuário, e estimular a resolução de problemas ambientados em situações cotidianas, conforme os Parâmetros Curriculares Nacionais (PCNs).

Palavras-chave: hiperdocumentos, Geometria Plana.

\footnotetext{
Mestre em Ciência da Computação - UFRGS, Doutoranda do PGIE / UFRGS, Professora da Faculdade de Informática da ULBRA

Mestre em Ciência da Computação - UFRGS, Doutorando do PGIE / UFRGS, Professor da Faculdade de Informática da ULBRA

*** Mestre em Ensino de Ciências e Matemática - PUCRS

Doutor em Ciência da Computação - França, Professor do PGIE e do PGCC / UFRGS

V.3 $\mathrm{N}^{\circ} 2$, Novembro, 2005
} 


\section{Introdução}

Segundo os Parâmetros Curriculares Nacionais (1996) "parte dos problemas referentes ao ensino de Matemática estão relacionados ao processo de formação do magistério, tanto em relação à formação inicial como à formação continuada. Decorrentes dos problemas da formação de professores, as práticas na sala de aula tomam por base os livros didáticos, que infelizmente, são muitas vezes de qualidade insatisfatória. A implantação de propostas inovadoras, por sua vez, esbarra na falta de uma formação profissional qualificada, na existência de concepções pedagógicas inadequadas e, ainda, nas restrições ligadas às condições de trabalho”.

A partir dessas considerações e destacando uma tendência mundial em melhorar as condições de ensino por meio da incorporação de novos recursos didáticos na educação (Perrenoud, 2000), em especial do computador, surge o projeto descrito nesse artigo. Esse material em desenvolvimento, em consonância com as orientações didáticas atuais para a Matemática descritas nos PCNs, busca privilegiar situações de exploração, de resolução de problemas, de observação e entendimento do mundo, de aplicação dos conhecimentos em áreas interdisciplinares, através de recursos de multimídia e de simulação, em que o aluno é agente ativo do processo.

"Estudiosos do tema mostram que escrita, leitura, visão, audição, criação e aprendizagem são capturadas por uma informática cada vez mais avançada. Nesse cenário, insere-se mais um desafio para a escola, ou seja, o de como incorporar ao seu trabalho, apoiado na oralidade e na escrita, novas formas de comunicar e conhecer. (...) Embora os computadores ainda não estejam amplamente disponíveis para a maioria das escolas, eles já começam a integrar muitas experiências educacionais, prevendo-se sua utilização em maior escala a curto prazo”.(PCNs, 1996)

Esse material, portanto, poderá ser utilizado como recurso complementar ao estudo da Geometria Plana no Ensino Fundamental. Conforme orientação do professor, ou mesmo de forma autônoma, o aluno poderá utilizá-lo na escola, na biblioteca ou mesmo em casa, buscando explorar os conceitos e situações propostas, oportunizando interações ricas e respeitando os ritmos de aprendizagem.

O hiperdocumento modelado e prototipado, apresentado nesse artigo, trata-se de um ambiente multimídia, com fins didáticos, para suporte ao ensino e à aprendizagem da Geometria Plana Elementar. O material a ser produzido abarca competências e conteúdos a serem desenvolvidos em Geometria Plana, na disciplina de Matemática, no Ensino Fundamental. Assim, considera-se como potencial público-alvo desse produto multimídia os estudantes de $5^{\mathrm{a}}$ a $8^{\mathrm{a}}$ série desse nível de ensino.

O material a ser desenvolvido busca explorar conceitos de forma interativa, exigindo participação ativa e intencional do usuário, e estimular a resolução de problemas ambientados em situações cotidianas.

\section{Olhar sobre a Geometria, conforme os PCNs}

Os conceitos geométricos constituem parte importante do currículo de Matemática no Ensino Fundamental, porque, através deles, o aluno desenvolve um tipo especial de pensamento que lhe permite compreender, descrever e representar, de forma organizada, o mundo em que vive.

A Geometria é um campo fértil para se trabalhar com situações-problema e é um tema pelo qual os alunos costumam se interessar naturalmente. O trabalho com noções geométricas contribui para: a aprendizagem de números e medidas; a elaboração, organização e adequado preenchimento de tabelas; pois estimula o aluno a observar, 
perceber semelhanças e diferenças, identificar regularidades, descobrir leis que regem seqüências obtidas na prática, formular hipóteses, testar as mesmas e concluir.

Além disso, as orientações didáticas atuais apontam para propostas de trabalho a partir da exploração de objetos do mundo físico, de obras de arte, pinturas, desenhos, esculturas, artesanato, bem como de conteúdos ligados a mais de uma disciplina, permitindo ao aluno estabelecer conexões entre a Matemática e outras áreas do conhecimento.

De forma mais objetiva, espera-se que o aluno possa realizar:

- percepção de elementos geométricos nas formas da natureza e nas criações artísticas;

- representação de figuras geométricas;

- identificação de semelhanças e diferenças entre polígonos, usando critérios como número de lados, número de ângulos, eixos de simetria, etc;

- exploração de características de algumas figuras planas, tais como: rigidez; a regularidade ou não das figuras quanto aos lados e/ou quanto aos ângulos internos/externos; o formato: triangular, quadrangular, hexagonal ou outros; a posição relativa entre lados de uma figura: os paralelos, os perpendiculares, bem como lados oblíquos e a interferência que produzem nos ângulos internos e externos de uma figura geométrica, etc;

- medidas de perímetro e área das figuras planas;

- composição e decomposição de figuras planas e identificação de que qualquer polígono pode ser composto a partir de figuras triangulares.

\section{Proposta do Hiperdocumento}

$\mathrm{Na}$ Internet é bastante comum encontrar tutoriais parciais sobre o tema, que apresentam conceitos geométricos de maneira estática. Por outro lado, há inúmeros "softwares de geometria dinâmica" que permitem ao aluno expressar-se através da sua linguagem. Não há, porém, um material que reúna, didaticamente, conceitos da Geometria Plana, ilustrados por mídias variadas (texto, som, vídeo, imagens estáticas e interativas), problemas desafiadores e sugestões de materiais de apoio.

O material multimídia proposto pretende reunir os itens expostos acima, modelado a partir das figuras elementares da Geometria Plana: triláteros, quadriláteros, pentágonos, hexágonos, n-láteros e círculos. Para cada tipo de figura, são abordados: conceitos, representação da forma, subclassificações, número e relações de lados, número e relações de ângulos, diagonais, perímetro, área, reconhecimento das formas do dia-a-dia, resolução de problemas com raciocínio geométrico. O conteúdo, sempre que possível, deve ser ilustrado com vídeos representativos do mundo real e figuras interativas para exploração por parte do aluno.

A articulação dos conhecimentos na resolução de problemas é fundamental e, portanto, os exercícios propostos devem combinar situações que exigiam o uso de raciocínio geométrico e não a mera aplicação de um conceito isolado. Faz-se necessário, também, oferecer uma base de materiais de apoio complementar aos assuntos abordados.

\section{Modelagem}

A modelagem do hiperdocumento baseou-se nas técnicas descritas no HMT ("Hypermedia Modeling Technique"), desenvolvido por Nemetz (1995). Esse método apóia as fases de modelagem e projeto de aplicações hipermídia através de quatro 
modelos, que auxiliam nas modelagens conceitual (modelo de objetos e modelo de hiperobjetos), navegacional e de interface, apresentados na seqüência.

\subsection{Modelo de Objetos}

O modelo de objetos descreve a semântica do domínio da aplicação, através da representação das classes de objetos do domínio da aplicação, de suas associações e de seus atributos. $\mathrm{O}$ modelo pode ser simplificado através do conceito de herança.

A Figura 1 traz o modelo de objetos simplificado para a aplicação hipermídia proposta: cada figura geométrica, com seus atributos, tem uma classificação quanto ao número de lados e apresenta um ou mais problemas relacionados, bem como um ou mais materiais de apoio. Para cada classificação, há uma ou mais figuras (por exemplo, são quadriláteros os quadrados, os retângulos, os trapézios...).

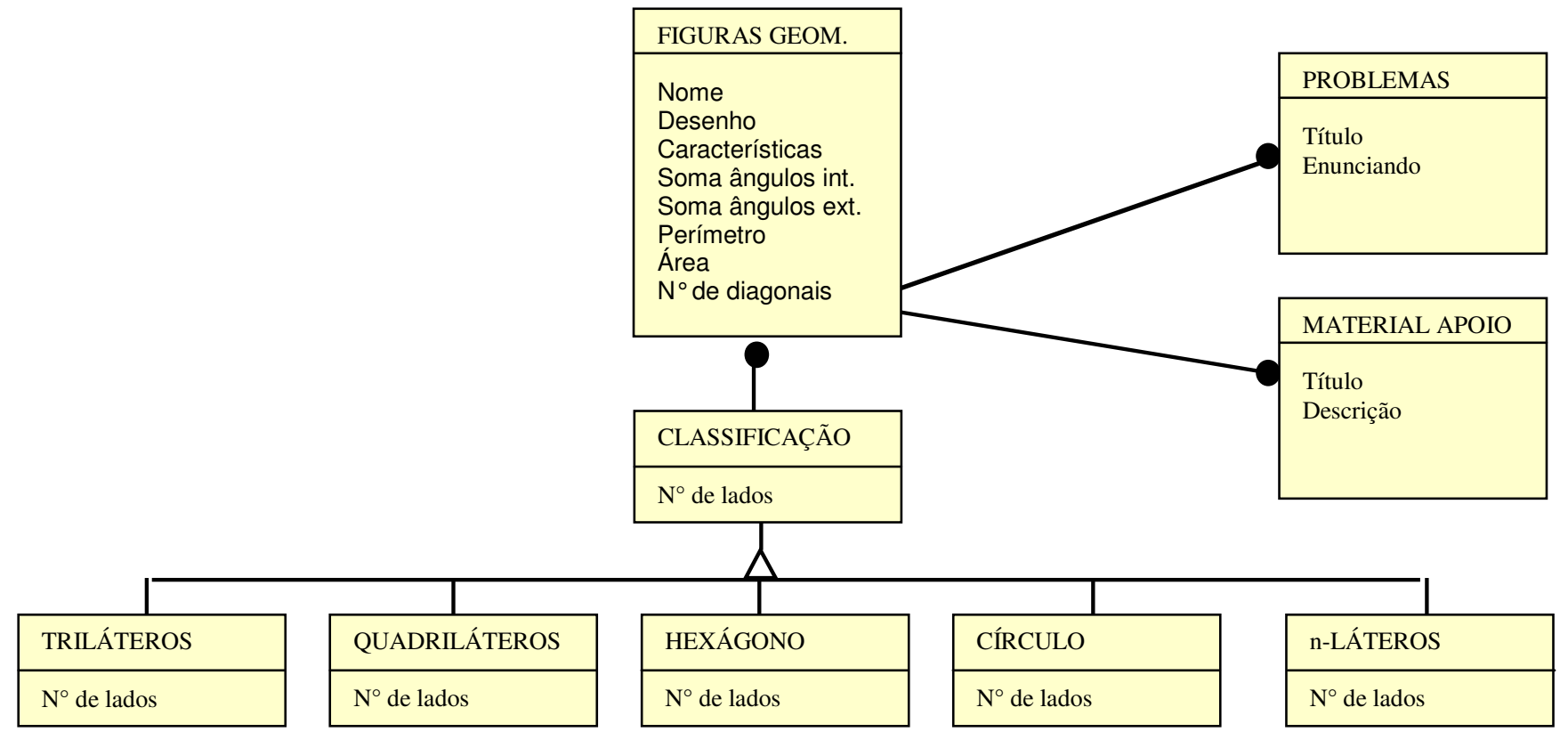

Figura 1. Modelo de Objetos Simplificado

\subsection{Modelo de Hiperobjetos}

No modelo de hiperobjetos refina o modelo de objetos, podendo acrescentar-se: novas classes e associações não presentes no modelo anterior; classes específicas para os objetos multimídia que serão incorporados (descrevendo seus comportamentos através das operações realizáveis sobre elas); e identificando classes abstratas (marcadas com borda dupla).

A Figura 2 apresenta o modelo de hiperobjetos do projeto. Cabe destacar novas associações identificadas, como a de uma figura geométrica poder referenciar outras (por exemplo, para calcular a área de um trapézio, é possível estabelecer relação com o cálculo da área de um triângulo). Em relação às mídias, por uma questão de simplificação, as operações não foram postas. Um problema tem um texto e, opcionalmente, áudio, imagem estática e imagem interativa para exploração. É possível observar, também, que toda figura geométrica, além dos seus atributos, terá um texto, um áudio que a apresenta, um vídeo com explicações ou exemplos adicionais, uma imagem estática prototípica e uma imagem interativa para exploração do usuário. 


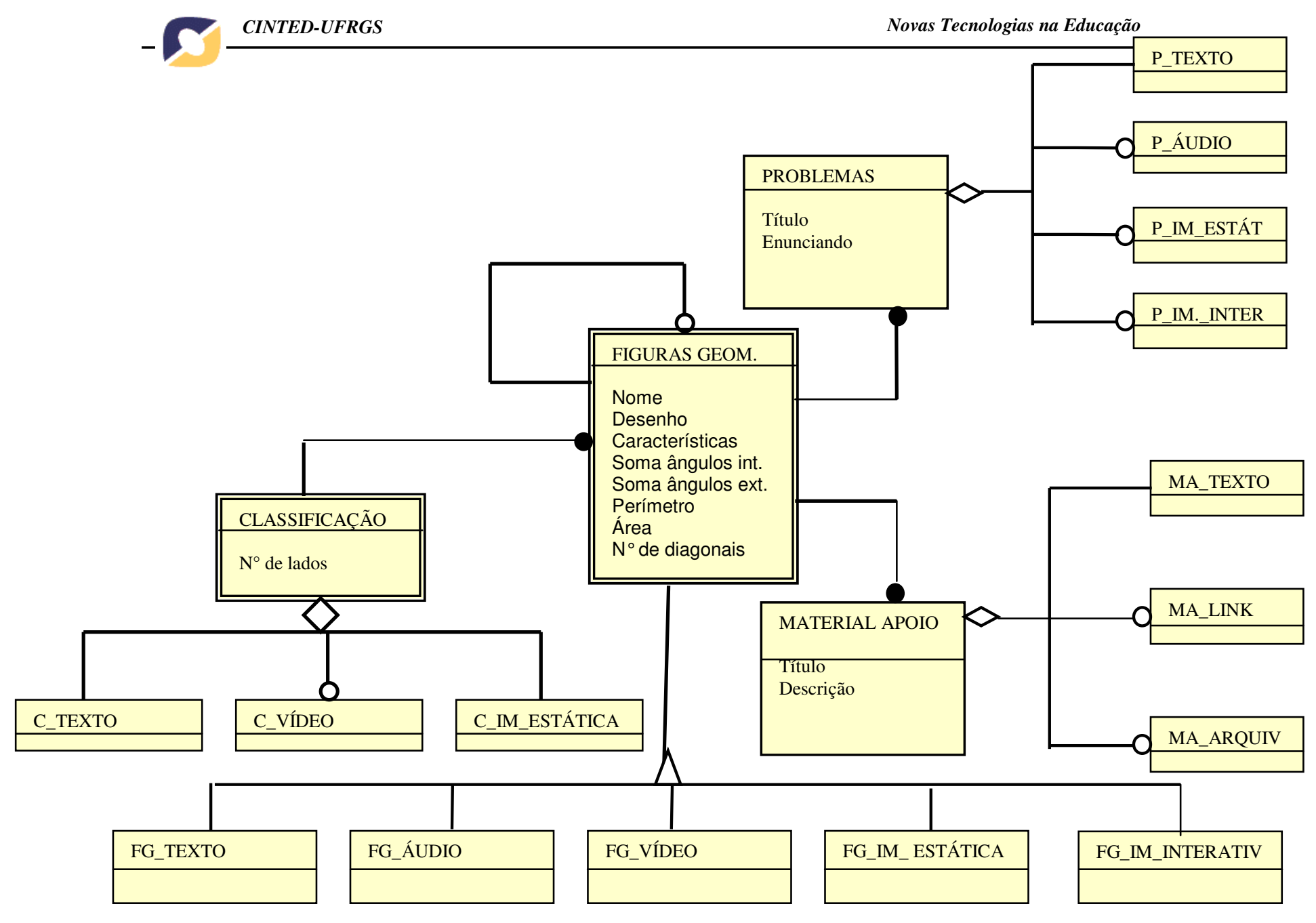

Figura 2. Modelo de Hiperobjetos

\subsection{Modelo de Navegação}

O modelo navegacional é um elemento importante para descrever os caminhos possíveis dos usuários em interação com o material hipermídia, buscando reduzir a sobrecarga cognitiva e a desorientação. O primeiro passo é gerar uma tabela com todas as associações e cardinalidades, visualizando, assim, todas os caminhos de acesso aos objetos. A partir da análise da tabela, então, identificam-se os elos, as estruturas de acesso e os pontos de entrada que serão implementados, bem como se definem os contextos navegacionais.

A Figura 3 apresenta o diagrama de navegação do hiperdocumento de Introdução à Geometria Plana. Há três pontos de entrada: Classificação (quanto ao número de lados - triláteros, quadriláteros...), Figuras Geométricas (triângulo, quadrado, retângulo, paralelogramo..., círculo), ou Problemas (escolha de exercícios). As setas que ligam as classes apontam os elos de ligação existentes. A partir de cada ponto de entrada, a forma de navegação disponível é por roteiro guiado indexado, isto é, o usuário pode selecionar as opções existentes que se relacionam ao contexto navegacional em que se encontra.

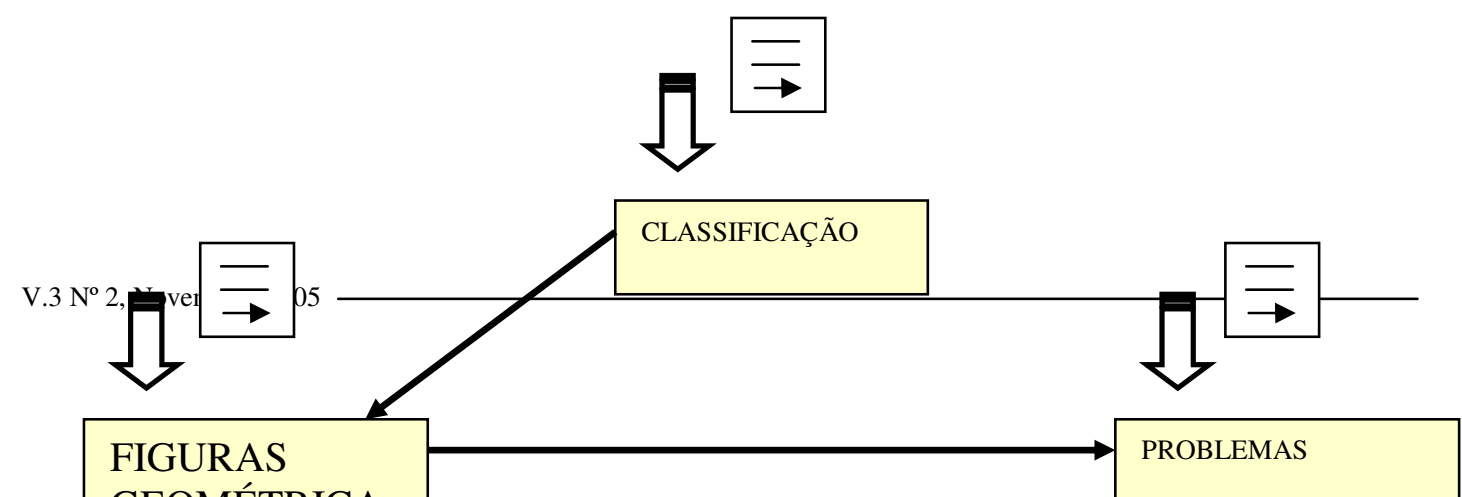




\section{Figura 3. Diagrama de Navegação}

\subsection{Modelo de Interface}

O modelo de interface descreve como o usuário perceberá os objetos hipermídia. Portanto, além de poder basear-se em alguma metáfora (livro, viagem, mapa, linha do tempo...), é desejável esboçar o layout de tela, apresentando em quantas áreas será dividida, o que cada uma conterá e qual a identidade visual que apresentará.

A Figura 4 apresenta uma tela extraída do protótipo, com o layout padrão da aplicação hipermídia. Na parte superior, encontra-se a identificação (fictícia) do grupo de trabalho. Ao centro, está a área de conteúdos, com os elos relacionados. Na parte inferior, apresenta-se a área de navegação num mesmo contexto e a possibilidade de buscar um novo ponto de entrada.

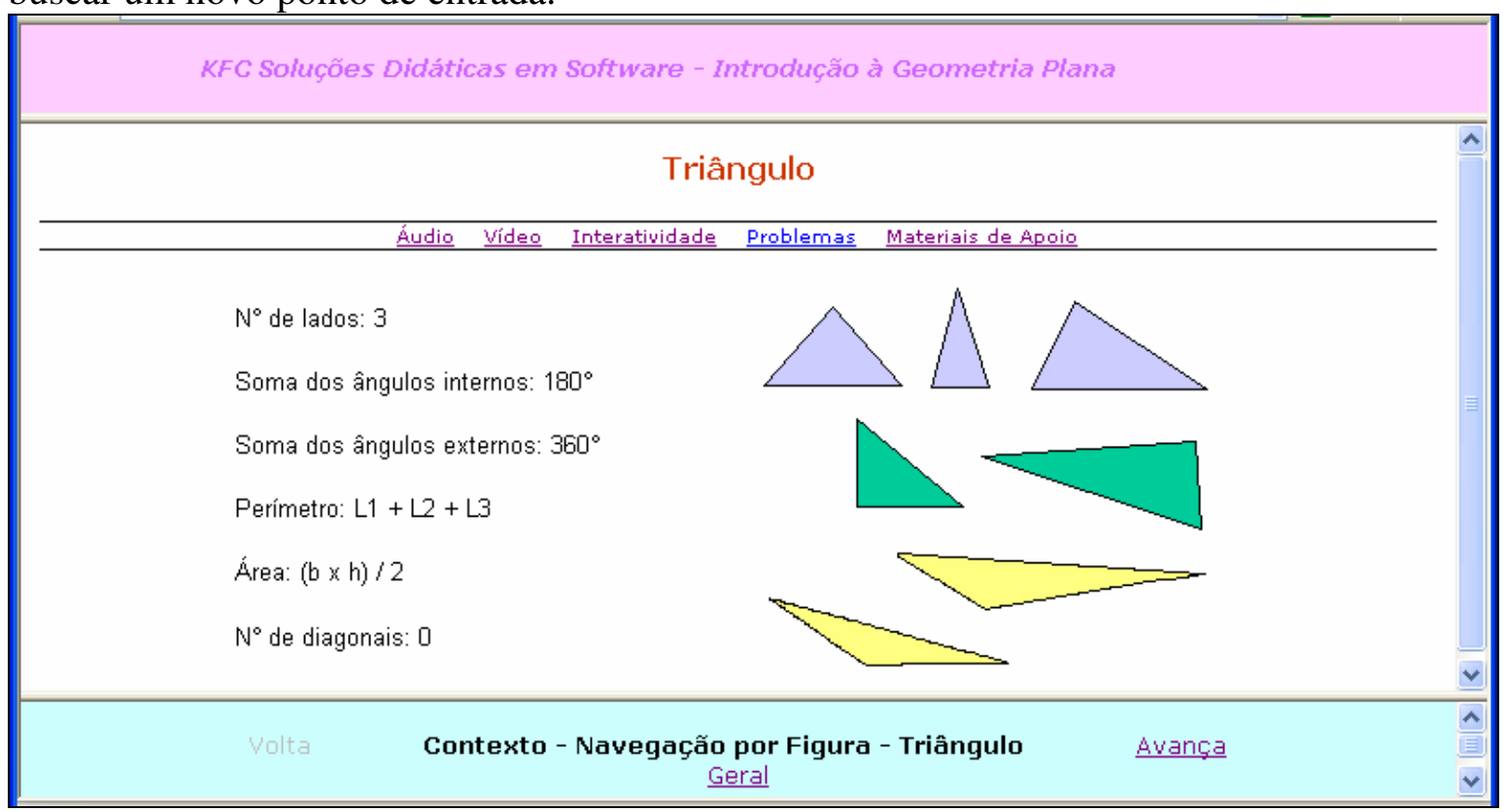

Figura 4. Exemplo de Interface

\section{Protótipo}

O protótipo modelado foi desenvolvido através de páginas html. As mídias foram geradas com o auxílio de diversos editores de imagem, de áudio e de vídeo. Cabe destacar aqui o potencial de articular o uso de mídias não apenas para ilustrar os conteúdos de forma rica e sensibilizar o usuário por diferentes canais sensoriais, mas para possibilitar a interatividade na exploração das diversas figuras e conceitos. 


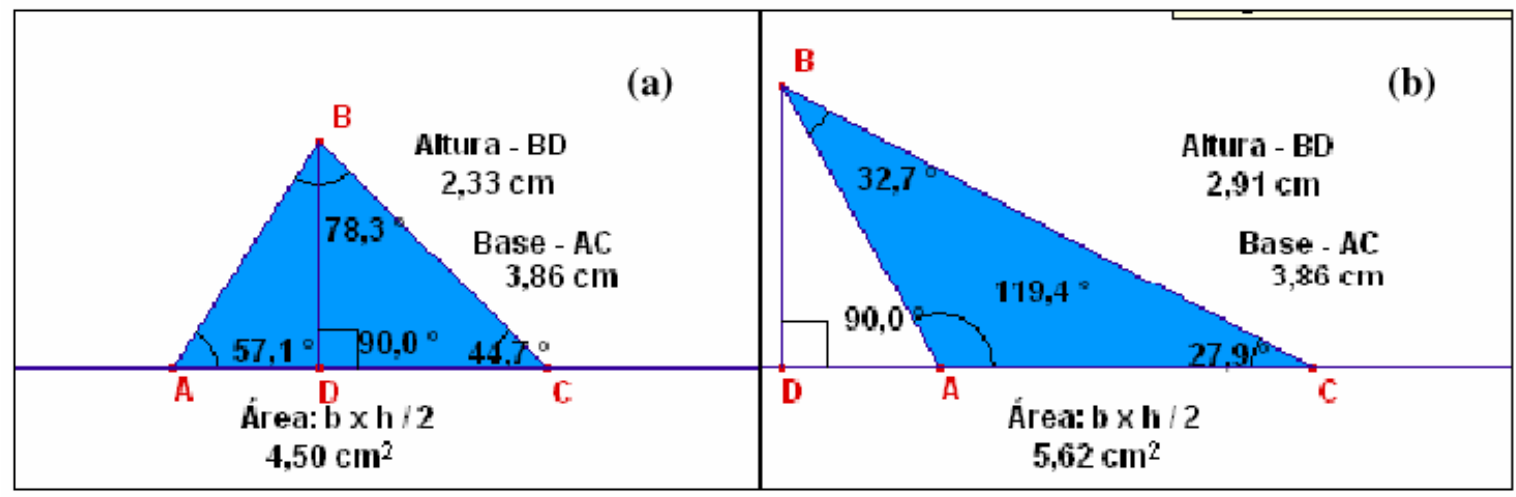

Figura 5 - Exemplo de Figura Interativa - antes (a) e durante (b) exploração

As figuras interativas (Figura 5) foram elaboradas no software Cabri Géomètre II e incorporadas ao hiperdocumento através de applets. Tal software permite explorar as figuras através da ação direta sobre elas. Apresentam-se modelos sobre os quais o aluno vai interagir, manipulando-os, buscando compreendê-los, estabelecendo relações e construindo conceitos. Diferentemente da representação de um objeto matemático com lápis e papel, na tela do computador é possível alterar diretamente as representações de tais objetos, buscando fazê-los variar e, a partir de tais variações, abstrair a invariância. De acordo com suas ações, uma representação é visualizada, servindo de base para a reflexão sobre suas concepções (Gravina, 1998).

\section{Considerações Finais}

Alicerçado na realidade nacional, que anseia por recursos didáticos que contribuam para a qualidade no processo de ensino e aprendizagem, surge o projeto descrito. A escolha da área de Matemática se justifica pelos baixos índices de aproveitamento dos alunos brasileiros, como divulgado em resultados recentes de testes internacionais (PISA), nos quais o Brasil tem freqüentemente disputado os últimos lugares. Com todas essas questões, urge desenvolver material de qualidade que possa ser largamente utilizado.

A implementação do protótipo, embora ainda não validado, aponta no caminho indicado pelos PCNs: desenvolver as competências dos alunos de maneiras inovadoras, interativas e interdisciplinares. É interesse do grupo levar a frente o projeto, desenvolvendo uma versão mais elaborada. Para tanto, o grupo pretende submeter o projeto a órgãos fomentadores, captando recursos para investir na produção de mídias e de conteúdos.

\section{Bibliografia}

Gravina, Maria Alice; Santarosa, Lucila Maria Costi. (1998) "A Aprendizagem da Matemática em Ambientes Informatizados”, In: Informática na Educação: Teoria e Prática - vol. 1, n. 1. Porto Alegre: UFRGS - Curso de Pós-Graduação em Informática na Educação.

Kampff, Adriana Justin Cerveira; Machado, José Carlos de Souza; Cavedini, Patrícia. (2004) Novas Tecnologias e Educação Matemática. In: X Workshop de Informática na Educação - XXIII Congresso da Sociedade Brasileira de Computação. Salvador, BA.

Nemetz, Fábio. (1995) HMT: Modelagem e Projeto de Aplicações Hipermídia. Porto Alegre: CPGCC/UFRGS. 
Nemetz, Fábio. (1995) Uma Técnica para Modelagem de Aplicações Hipermídia e um Exemplo de Uso. In: Seminário Integrado de Software e Hardware. SBC: Canela, RS. Anais. Porto Alegre: Instituto de Informática da UFRGS. Vol.1. P.261-274.

Parâmetros Curriculares Nacionais Matemática - Matemática Ensino Fundamental. (1996)

http://www.bibvirt.futuro.usp.br/textos/humanas/educacao/pcns/fundamental/matema tica.html\#2.3.1.3.

Perrenoud, Philippe. (2000) Dez novas competências para ensinar. Porto Alegre: Artes Médicas Sul, 2000. 